(๐ А.Л. Курчаков ${ }^{1 *}$, И.А. Лихова ${ }^{2}$

${ }^{1}$ Московский медицинский университет «Реавиз», Москва, Россия

${ }^{2}$ Первый Московский государственный медицинский университет им. И.М. Сеченова (Сеченовский университет), Москва, Россия

Роберт Джеймс Грейвс - выдающийся специалист в области медицины, внесший существенный вклад в ее развитие. Основной путь ученого начался отнюдь не с медицинской практики, а с путешествий, которые побудили его начать и плодотворно осуществлять свою научную деятельность в будущем.

Научная деятельность Роберта Джеймса Грейвса сформировала особые предпосылки для развития медицинского образования и целых областей медицины. Практика студентов, согласно его модели обучения, была нетипичной, однако о ней довольно позитивно отзывались многие специалисты, например, такие как Т. Дж. МакКенн и Арман Труссо.

Он вошел в историю тем, что открыл аутоиммунное заболевание щитовидной железы, вызывающее гипертиреоз, а также известен как врач, внесший вклад в развитие эндокринологии, кардиологии, инфекционных заболеваний и неврологии.

КЛЮЧЕВЫЕ СЛОВА: Р.Д. Грейвс; Дублинская медицинская школа; Т.Дж. МакКенн; Арман Труссо; медицина.

\title{
TO THE 225TH ANNIVERSARY OF THE BIRTH OF ROBERT JAMES GRAVES
}

\author{
(c) Artem L. Kurchakov*, Izabella A. Likhova²
}

${ }^{1}$ Moscow Medical University «Reaviz», Moscow, Russia

2I.M. Sechenov First Moscow State Medical University, Moscow, Russia

Robert James Graves is an eminent medical practitioner who has made significant contributions to this field. The main path of the scientist began by no means with medical practice, but with extensive travels that prompted him to start and fruitfully carry out scientific activity in the future.

The scientific activity carried out by Robert James Graves throughout his life formed special preconditions for the development of medical education and entire fields of medicine. The practice of students, according to his teaching model, was not typical, but many experts in this field spoke about it quite positively, for example, such as T.J. McKenn and Armand Trousseau. He made history 180 years ago by discovering an autoimmune disease, which causes hyperthyroidism, he was known as a physician whose contribution covered the entire field of endocrinology, cardiology, infectious diseases and neurology.

KEYWORDS: R.D. Graves; Dublin Medical school; T. J. McKenn; Armand Trousseau; medicine.

\section{БИОГРАФИЯ}

Роберт Джеймс Грейвс родился в Дублине в 1796 г., в тяжелые времена не только для Ирландии, но и для всего мира. В конце XVIII в. в Европе натуральная оспа уносила множество жизней. Семья доктора Грейвса, которая прибыла в Ирландию во время завоевания страны Оливером Кромвелем (1649-1653), была достаточно богатой и хорошо зарекомендовала себя в обществе. Его отец, Ричард Грейвс, и дедушка по материнской линии были старшими научными сотрудниками Тринити-колледжа в Дублине, куда в 1811 г. он поступил к своему зятю Томасу Мередиту, получив раннее образование в Даунпатрике и Дублине.

После блестящей студенческой карьеры в области искусств он получил степень доктора медицины в 1818 г. и уехал в Лондон, чтобы изучать хирургию у сэра Уильяма
Близарда. Одним же из учеников самого Роберта Грейвса был Уильям Стоукс (1804-1878), который в последующем стал его коллегой. Еще одним его учеником был Ричард Таунсенд, в дальнейшем получивший докторскую степень в Эдинбурге в 1824 г. [1].

Закончив медицинский факультет в 22 года, в 1818 г., в Тринити-колледже Дублина, где его признали лучшим студентом и наградили золотой медалью, Грейвс в дальнейшем получил медицинскую лицензию от RCPI (Королевский колледж врачей Ирландии), где в будущем сам стал президентом. После этого он провел следующие три года, путешествуя по континенту между стажировками в качестве наблюдателя в медицинских школах Эдинбурга, Берлина, Вены, Геттингена, Гамбурга, Копенгагена, а также Франции и Италии [2].

Роберт Грейвс очень любил путешествовать, обладал исключительным талантом к языкам и, находясь 
в континентальной Европе, он провел десять дней в тюрьме в Австрии, когда путешествовал пешком без паспорта; власти считали его немецким шпионом, и никто из них не верил, что ирландец может так хорошо говорить на их языке. Согласно историческим документам, по дороге из Генуи в Сицилию Р. Грейвс спас корабль и его мятежную команду, приняв на себя командование во время шторма в Средиземном море. На судне возникла течь, насосы вышли из строя, и команда попыталась покинуть судно: Грейвс продырявил одну спасательную шлюпку топором, сообщив экипажу: «Давайте утонем вместе, жаль расставаться с хорошей компанией», а затем приступил к ремонту насосов кожей из своей обуви, таким образом спасая корабль и всех на борту.

Однако его странствия были не ради приключений. Главной целью Грейвса было продолжить медицинское образование. Своей миссией он сделал плодотворное знакомство с известными врачами и физиологами континента, и за время путешествий смог накопить те знания, которые в результате привели к совершенствованию медицины в Ирландии и открыли абсолютно новую эру в медицинском обучении [3].

\section{НАУЧНАЯ ДЕЯТЕЛЬНОСТЬ}

По возвращении в 1821 г. из путешествий Грейвс был назначен штатным врачом в больнице Мит, главной государственной больнице в Дублине. Там он ввел систему клинического и научного обучения, которой восхищался в Европе. В 1824 г. Грейвс основал медицинскую школу на Парк-стрит. Он начал революцию в клиническом обучении: лекции по-прежнему читались на латинском языке, однако Р. Грейвс посчитал целесообразным отказаться от него в пользу английского языка, тем самым сделав обучение более доступным для всех учащихся.

Он также ввел очередное важное изменение в ирландском медицинском образовании: в Германии студенты принимали участие в обходах пациентов вместе с врачами, Грейвс стал вводить данный метод обучения в Ирландии. Под его пристальным руководством студенты имели возможность наблюдать за пациентами в больнице, задавать все интересующие вопросы, помогать врачу при первичном опросе пациента, а также в составлении плана обследования и лечения [4].

Его знаменитое «обучение у койки» продвигало идею, которая в наше время определяет современную медицину. Вопреки традиционным методам преподавания медицины, которые требовали от студентов обширных книжных знаний, но небольшого практического опыта, Грейвс заставлял своих студентов осматривать пациентов, писать истории болезни и анализировать физические данные больного и методы лечения у постели пациента. По его мнению, «студент должен наблюдать за прогрессом и последствиями болезни с самого ее начала, ежедневно осматривать пациента и делать выводы во время всего периода лечения». Грейвс даже призвал своих учеников узнать стоимость рецептов, чтобы, когда они начнут заниматься частной практикой, могли учитывать финансовое положение пациента, прописывая соответствующие лекарственные средства. Он считал, что полное изучение болезни возможно при понимании ее не только как теоретической системы,

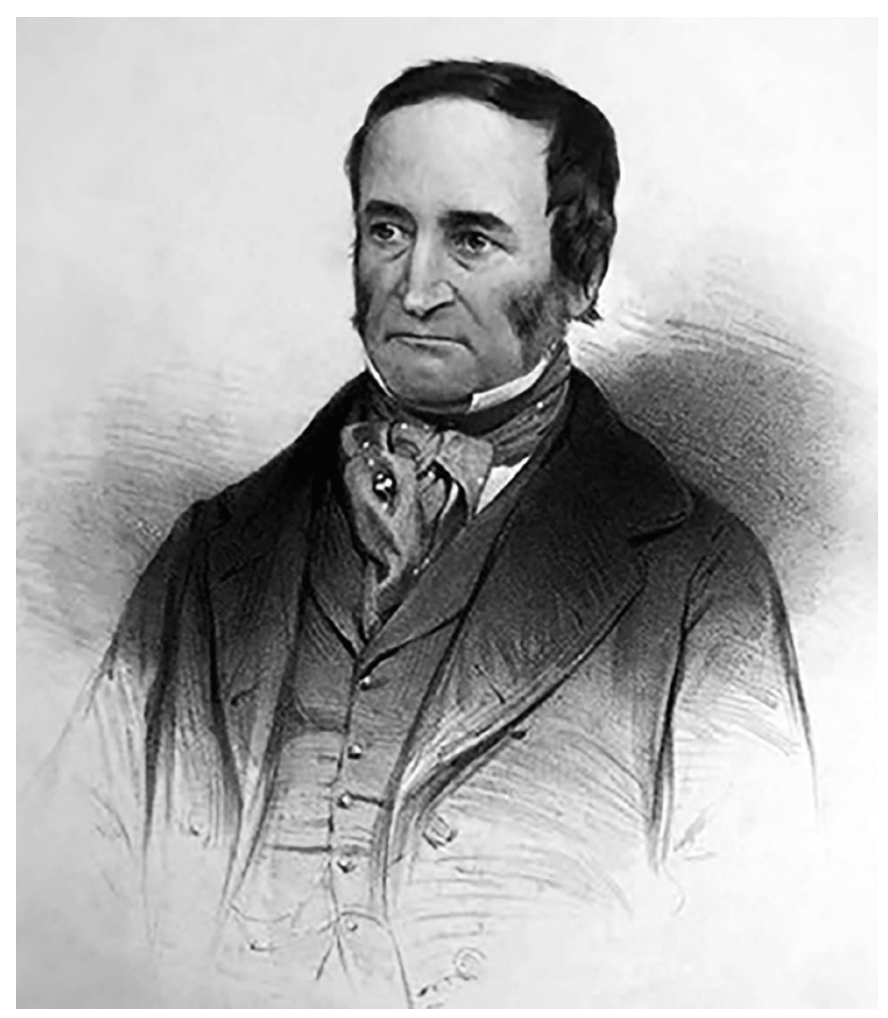

Рисунок 1. Доктор Роберт Джеймс Грейвс.

а состояния, которое воплощено в том или ином пациенте. Также он предложил теорию, что смертельные случаи в больницах зачастую происходили из-за равнодушного отношения к пациентам. Доктор Грейвс осуществлял на практике то, на чем акцентировал внимание во время преподавания. Его знаменитый учебник «Клинические лекции по медицинской практике» был издан в 1843 г. и завоевал огромное признание в Европейских странах. Миссия Роберта Грейвса заключалась в том, чтобы преобразовать систему преподавания, соответствуя которой, все учащиеся без обследования, анализа, выводов и постоянного внимания к пациенту не могли бы обучаться [4].

Вклад Р. Грейвса в выявление гипертиреоза явился результатом его клинического мастерства. Он был одним из первых врачей, который целиком смог описать диффузно-токсический зоб. Грейвс сообщил о трех молодых женщинах с тахикардией и увеличением щитовидной железы и о четвертой с тяжелым экзофтальмом, которую ему направил коллега Уильям Стоукс: «Глазные яблоки были заметно увеличены, до такой степени, что веки не могли закрыться во время сна». Также он описал симптом учащенного сердцебиения у пациента. Оно было настолько сильным, что его можно было слышать, даже когда ухо врача располагалось на расстоянии более чем четыре фута от груди больного. Грейвс считал увеличение щитовидной железы вторичным по отношению к патологическому усилению функции сердца. В связи с этим он высказывал теорию: «Совершенно очевидно, господа, что, если учащенное сердцебиение при функциональных пороках сердца способно вызвать его отек (гипертрофию), вполне возможно ожидать и отека от данной железы, так как учащенное сердцебиение происходит из-за органического поражения сердца». Кроме гипертиреоза, Грейвс описал ангионевротический отек, 
склеродермию, эритромелалгию и миоз при инсульте. В 1834 г. Грейвс прочитал ряд лекций на тему эндокринных заболеваний, которые в дальнейшем были опубликованы в 1835 г. в рамках клинических лекций Лондонского медицинского общества [5].

В Мерзебурге, в Германии, Карл А. фон Базедов описал тахикардию, экзофтальм и зоб, так называемую мерзебургскую триаду, и опубликовал данные в 1840 г. Хотя Базедов и описал многие из основных особенностей того, что мы теперь знаем как гипертиреоз, его публикация была на 5 лет позже, чем у Грейвса. Несмотря на более позднюю публикацию, во многих странах это заболевание называют базедовой болезнью, а в англоязычном мире и по сей день сохраняется названиеболезнь Грейвса».

Клинические лекции Грейвса по медицинской практике, которые были опубликованы в 1848 г., обеспечили ему незыблемую репутацию. Из числа нововведений, представленных в лекциях, можно назвать определение частоты сердечных сокращений с использованием часов, а также практику кормления пациентов с лихорадкой вместо того, чтобы отказывать им В питании. В то время рекомендовали голодовку как «непременное условие при лечении лихорадки». Грейвс шутливо просил, чтобы его эпитафия гласила: «Он кормил лихорадку» [6].

Как сказал Т. Дж. МакКенн, доктор медицинских наук, профессор кафедры эндокринологии и сахарного диабета: «Главным вкладом Грейвса в медицину стало инициирование учебных процессов». Кроме того, «он привел пример академического врача, чьи руководящие принципы могут быть с пользой приняты теми, кто стремится к академической карьере».

В описании Армана Труссо, выдающегося французского врача того же времени, Грейвс предстает как «прекрасный учитель, клиницист, внимательный наблюдатель, глубокий философ, гениальный художник»; он призывает восхищаться тем, что сделал Грейвс, а именно расширил клиническую практику, сделал ее более полезной и плодотворной [7].

\section{ЗАКЛЮЧЕНИЕ}

Нет сомнений, что Роберт Джеймс Грейвс был заслуженно награжденным и признанным гением своего времени, который совершил большой вклад в медицину.

Своим примером и учением он помогал студентам добиваться поставленных целей и становиться учеными в сфере медицины и не только. Сделал немало открытий, изучив неизвестные болезни, найдя лечение

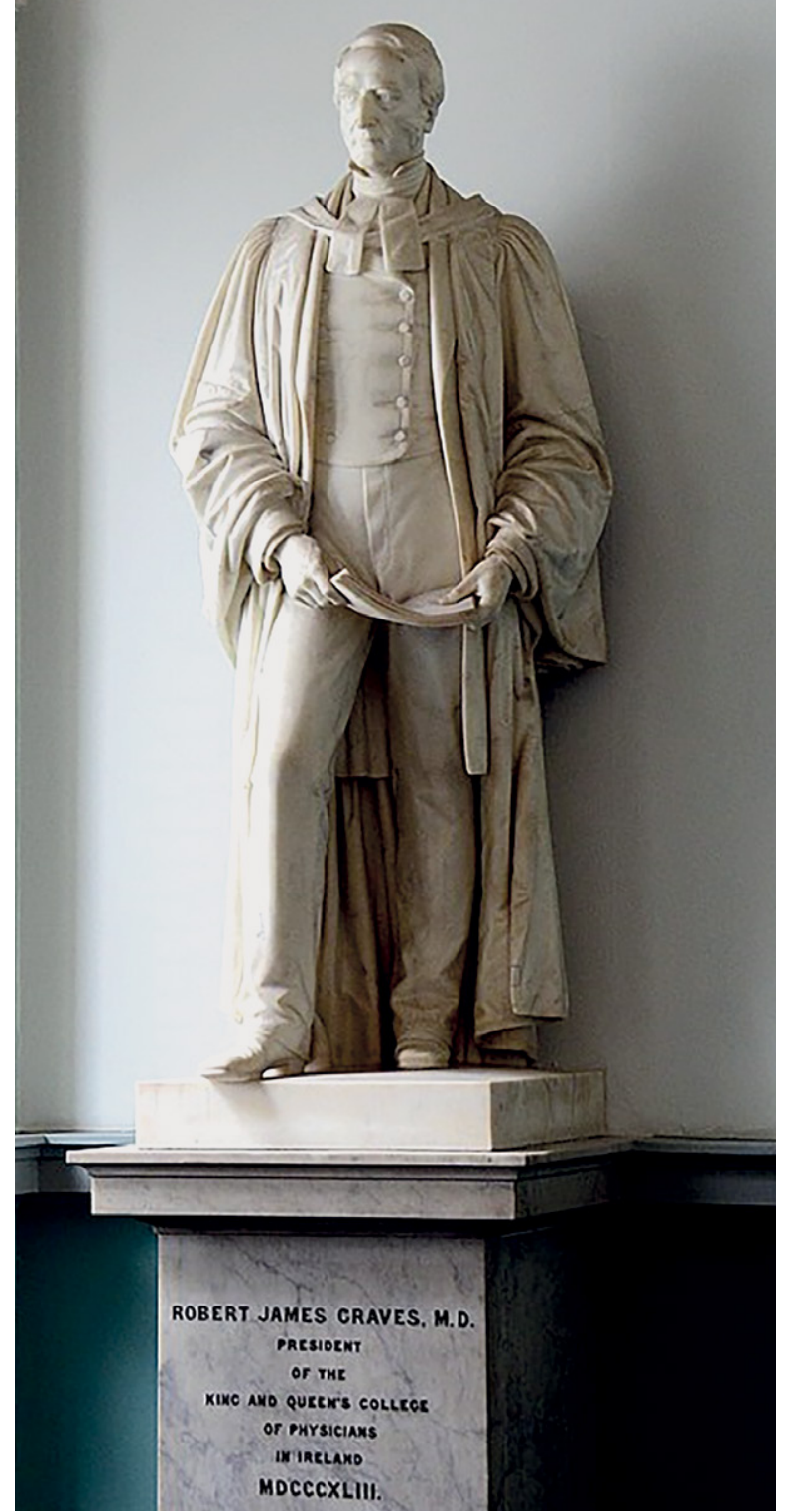

Рисунок. 2. Статуя Роберта Джеймса Грейвса в натуральную величину в Королевском колледже врачей Ирландии.

и пути в реабилитации. Студенты, коллеги - все признавали его мастерство, профессионализм и человеческие качества.

Его статуя (рис. 2) была установлена в Королевском колледже врачей Ирландии в 1878 г. и по сей день является частым местом паломничества для тиреоидологов. В течение многих лет его изображение было на логотипе Американской тиреоидологической ассоциации (АТА). Сейчас на логотипе изображена щитовидная железа.

\section{СПИСОК ЛИТЕРАТУРЫ | REFERENCES}

1. Роберт Джеймс Грейвс: 1796-1853. Доступно по: https://www.healio.com/ news/endocrinology/20120325/robert-james-graves-1796-1853. Ссылка активна на: 28.07.2020.

2. Роберт Джеймс Грейвс. Доступно по: https://www.eurothyroid.com/ about/met/graves.html. Ссылка активна на: 28.07.2020.

3. Jay V. Dr Robert James Graves. Arch Pathol Lab Med. 1999;123(4):284 doi: https://doi.org/10.5858/1999-123-0284-DRJG

4. Whitehead RW. Robert James Graves, physician, educator, scientist. Circulation. 1969;39(6):719-721. doi: https://doi.org/10.1161/01.cir.39.6.719
5. Роберт Джеймс Грейвс. Доступно по: http://www.mrcophth.com/ophthalmologyhalloffame/graves.html. Ссылка активна на: 28.07.2020.

6. Ирландский доктор старше своей жизни. Доступно по: https://www.medicalindependent.ie/a-larger-than-life. Ссылка активна на: 28.07.2020.

7. Роберт Джеймс Грейвс. Доступно по: https://www.britannica.com/biography/Robert-James-Gra. Ссылка активна на: 28.07.2020. 


\section{ИНФОРМАЦИЯ ОБ АВТОРАХ [AUTHORS INFO]}

*Курчаков Артем Леонидович, врач-лечебник [Artem L. Kurchakov, MD]; 119991, Москва, ул. Трубецкая, д. 8, стр. 2 [address: 8-2 Trubetskaya str., Moscow 119991, Russia]; ORCID: 0000-0002-7880-3255; e-mail: pirseaidan@gmail.com

Лихова Изабелла Арсеновна, врач-лечебник [Izabella A. Likhova, MD], ORCID: 0000-0002-4796-0231;

eLibrary SPIN: 2646-0969; e-mail: Izabellalihova@yandex.ru

*Автор, ответственный за переписку.

\section{ЦИТИРОВАТЬ}

Курчаков А.Л., Лихова И.А. Жизнь и наследие Хакару Хашимото // Клиническая и экспериментальная тиреоидология. 2021. — Т. 17. — №2. — С. 16-19. doi: https://doi.org/10.14341/ket12557

Рукопись получена: 02.08.2020. Одобрена к публикации: 09.07.2021

\section{TO CITE THIS ARTICLE}

Kurchakov AL, Likhova IA. Life and heritage of Hakaru Hashimoto To the 225th anniversary of the birth of Robert James Graves. Clinical and experimental thyroidology. 2021;17(2):16-19. doi: https://doi.org/10.14341/ket12557

Received: 02.08.2020. Accepted: 09.07.2021 